Introduzindo o campo da literacia em saúde: conceito, usos e reflexões para a saúde pública

Introducing the health literacy field: concepts, applications and reflections for public health

Introducción al campo de la literacia en salud: concepto, usos y reflexiones para la salud pública

\title{
LITERACIA EM SAÚdE
}

$\sum_{i}^{n}$

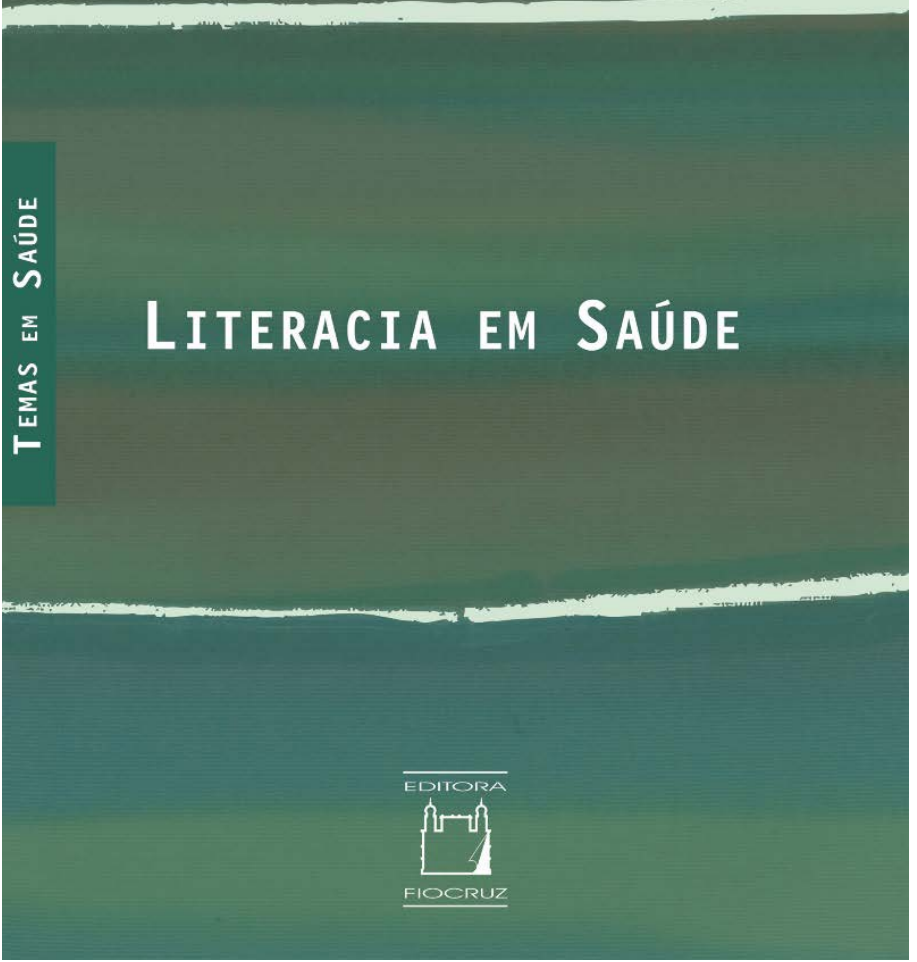

Leticia Barbosa ${ }^{1, a}$

leticiatbs@gmail.com | https://orcid.org/o000-0002-7341-26oX

${ }^{1}$ Fundação Oswaldo Cruz, Escola Nacional de Saúde Pública, Laboratório Internet, Saúde e Sociedade. Rio de Janeiro, RJ, Brasil. 


\section{RESUMO}

Como indivíduos buscam, avaliam, compreendem e utilizam informação sobre saúde? O livro Literacia em saúde oferece possíveis respostas e outras reflexões sobre essa questão. Literacia em saúde pode ser entendida como o conjunto de habilidades e competências acionado por indivíduos e coletividades para buscar, selecionar e dar significado às informações sobre saúde. Nessa perspectiva, o livro em questão discute as relações que se configuram entre a literacia em saúde e as possibilidades de uso das informações em saúde no cuidado próprio e do outro, além de apontar possíveis aplicações na estruturação de políticas públicas e no cotidiano do sistema de saúde e estabelecer um diálogo com a pandemia de Covid-19 em curso.

Palavras-chave: Letramento em saúde; Informação de saúde ao consumidor; Tomada de decisões; Serviços de saúde; Política de saúde.

\section{ABSTRACT}

How do individuals seek, assess, understand, and use health information? The book Health Literacy offers possible answers and other reflections on this issue. Health literacy can be understood as the set of skills and competences used by individuals and communities to seek, select, and give meaning to health information. From this perspective, the book discusses the relationships established between health literacy and the possibilities of using health information in the care of oneself and the other, in addition to pointing out possible applications of in the structuring of public policies and in the daily life of the health system and establishing a dialogue with the ongoing Covid-19 pandemic.

Keywords: Health literacy; Consumer health information; Decisions making; Health services; Health policy.

\section{RESUMEN}

¿Cómo buscan, evalúan, comprenden y utilizan las personas la información sanitaria? El libro Alfabetización en salud ofrece posibles respuestas y otras reflexiones sobre este tema. La alfabetización en salud puede entenderse como el conjunto de habilidades y competencias que utilizan los individuos y las comunidades para buscar, seleccionar y dar sentido a la información sanitaria. Desde esta perspectiva, el libro analiza las relaciones entre la alfabetización en salud y las posibilidades de utilizar la información en salud en el cuidado, además de señalar posibles aplicaciones en la estructuración de políticas públicas y en la vida diaria del sistema de salud y entablar un diálogo con la pandemia de Covid-19.

Palabras clave: Alfabetización en salud; Información de salud al consumidor; Toma de decisiones; Servicios de salud; Política de salud.

INFORMAÇÕES DO ARTIGO

Obra resenhada: PERES, Frederico; RODRIGUES, Karla Meneses; SILVA, Thais Lacerda e. Literacia em saúde. Rio de Janeiro: Editora Fiocruz, 2021. (Temas em Saúde).

Contribuição dos autores: a autora é responsável integralmente pelo texto.

Declaração de conflito de interesses: não há.

Fontes de financiamento: bolsa de pós-doutorado júnior pelo Programa Fiocruz de Fomento à Inovação (Inova Fiocruz)/ Fundação Oswaldo Cruz.

Considerações éticas: não há.

Agradecimentos/Contribuições adicionais: não há.

Histórico do artigo: submetido: 16 ago. 2021 | aceito: 16 ago. 2021 | publicado: 31 ago. 2021.

Apresentação anterior: não houve.

Licença CC BY-NC atribuição não comercial. Com essa licença é permitido acessar, baixar (download), copiar, imprimir, compartilhar, reutilizar e distribuir os artigos, desde que para uso não comercial e com a citação da fonte, conferindo os devidos créditos de autoria e menção à Reciis. Nesses casos, nenhuma permissão é necessária por parte dos autores ou dos editores. 
Diariamente, somos expostos a inúmeros tipos de informação que circulam em diferentes suportes e plataformas. Seja por meio de um cartaz na parede, do jornal na televisão, do vídeo no YouTube ou da mensagem por WhatsApp, consumimos de modo contínuo conteúdo informativo. Na atualidade, a busca, o consumo e a circulação de informação adquirem um caráter singular, sobretudo devido às tecnologias digitais. A disseminação da internet tem contribuído para um "dilúvio de informação" (LÉVY, 1999, p. 15). Nesse contexto, a saúde destaca-se enquanto um dos principais temas de conteúdos acessados e compartilhados.

Diante desse cenário, como indivíduos buscam, avaliam, compreendem e utilizam informação sobre saúde? O livro Literacia em saúde, escrito por Frederico Peres, Karla Meneses Rodrigues e Thais Lacerda e Silva, pesquisadores formados e atuantes no campo da saúde pública e coletiva, oferece possíveis respostas e outras reflexões sobre essa questão. Publicado em junho de 2021 pela Editora Fiocruz na coleção Temas em Saúde, ele apresenta ao leitor um panorama sobre o conceito e o campo da literacia em saúde. Tal como apontado pelos autores da obra, ainda que sua definição possa variar conforme áreas de estudo e referenciais teóricos, a literacia em saúde pode ser entendida como o conjunto de habilidades e competências acionado por indivíduos e coletividades para buscar, selecionar e dar significado às informações sobre saúde. Nessa perspectiva, o livro discute as relações que se configuram entre a literacia em saúde e as possibilidades de uso das informações em saúde no cuidado próprio e do outro, além de apontar possíveis aplicações do conceito na estruturação de políticas públicas e no cotidiano do sistema de saúde.

O texto é iniciado por uma seção de apresentação da obra, seguido por uma introdução geral ao tema e quatro capítulos. Embora estudos sobre o conceito tenham crescido nas últimas décadas, a literacia em saúde ainda é um termo relativamente novo e, por vezes, desconhecido do público em geral. Assim, para contextualizar o leitor acerca da discussão que será desenvolvida ao longo do livro, os autores destacam na 'Apresentação' a dimensão informacional presente em situações típicas do contexto da saúde e do cuidado - a leitura de um cartaz em uma unidade de saúde, a consulta do paciente com o médico, a pesquisa de informação sobre saúde na internet. Assim como apontam Peres, Rodrigues e Silva (2021), tais momentos, comuns do cotidiano, são atravessados por uma troca de informações, constituídas por diferentes signos e discursos, que: produzem sentidos e ações de saúde; implicam atores oriundos de contextos diversos; e acionam diferentes competências. Desse modo, envolvem, em maior ou menor medida, a dimensão da literacia em saúde. Ao trabalhar tais exemplos, os autores já dão pistas não só sobre a diversidade e a complexidade que o tema da literacia envolve, mas também sobre seu inevitável imbricamento nas dinâmicas, nas relações, nos processos e nas ações do campo da saúde. Tais aspectos são trabalhados ao longo das seções subsequentes.

A 'Introdução' do livro apresenta um panorama do assunto, abordando o conceito de literacia em saúde e os principais pontos de sua constituição, enquanto construto teórico e enquanto campo de estudo. A seção inclui apontamentos sobre a definição conceitual, as variações na nomenclatura, a utilização inadequada de outras expressões como sinônimo de literacia em saúde, e as mudanças na abordagem analítica e nas métricas adotadas em estudos da área ao longo das últimas décadas. Ao recapitular o processo histórico de composição do campo, os autores mostram que a literacia em saúde é um objeto de estudo relativamente recente. O uso do conceito no contexto da produção científica internacional data do fim da década de 1990, enquanto na produção nacional ocorre principalmente a partir de meados dos anos 2000. Pesquisas sobre o tema apresentaram crescimento na última década do século XX, sendo, portanto, um campo ainda incipiente.

Ainda que não apresente uma longa tradição enquanto objeto de estudo, Peres, Rodrigues e Silva (2021) destacam que a literacia em saúde configura-se um tema fundamental, uma vez que níveis baixos de literacia estão relacionados a piores resultados de saúde, tanto a nível individual quanto coletivo. Os autores 
também ressaltam que a literacia em saúde não deve ser confundida com letramento ou alfabetização em saúde, ou ainda ser limitada a uma perspectiva funcional, uma vez que apresenta especificidades e não se limita à educação formal e ao processo de ensinar e saber ler e escrever de acordo com a norma-padrão da língua em que o indivíduo se encontra.

Nesse sentido, Peres, Rodrigues e Silva (2021) apresentam os modelos desenvolvidos por Don Nutbeam e por Christina Zarcadoolas, Andrew F. Pleasant e David S. Greer, no início dos anos 2000, para apresentar ao leitor a perspectiva ampliada da literacia em saúde. Tais modelos apresentam, em certa medida, uma ruptura com as pesquisas que vinham sendo desenvolvidas até então, focadas nas habilidades funcionais de ler, escrever e interpretar textos e na aplicação de testes padronizados para mensurá-las. Nesses modelos, a literacia é pensada como fenômeno multidimensional, que envolve, além das habilidades funcionais, crenças, valores, identidades e diferentes saberes.

Na seção de introdução ao tema, é possível observar a importância que a literacia em saúde adquire no contexto atual, sobretudo naquilo que tange a interface entre informação, comunicação e saúde. Conforme discutido pelos autores, indivíduos e grupos acionam diferentes habilidades e competências para buscar, selecionar, avaliar e dar sentido a informações sobre saúde. Os modos como a informação é significada podem afetar seus usos no processo de tomada de decisão sobre saúde, incluindo as práticas de autocuidado e o acesso a serviços. Isso indica que, para pensar em estratégias de comunicação em saúde, é necessário ir além da dimensão do fornecimento de informação e considerar as diferentes competências que os sujeitos usam para acessar e compreender o conteúdo informativo e as relações entre tais competências, os usos da informação e seus efeitos na tomada de decisão de indivíduos e coletividades.

Diante da apresentação de um conceito ainda pouco conhecido, o leitor pode ter dificuldades em vislumbrar como empregá-lo na prática. Nesse sentido, o primeiro capítulo do livro, denominado 'Aplicações da literacia em saúde nas práticas de saúde', contribui para ampliar a compreensão acerca dos possíveis usos. Os autores apontam que há inúmeras formas de utilização da literacia no campo da saúde; entretanto, no capítulo, a discussão das aplicações se restringe a quatro áreas: materiais informativos ou educativos sobre saúde; cuidado e atenção à saúde; alimentação e nutrição; e promoção da saúde. Ainda que as áreas apresentem especificidades, é possível notar que alguns aspectos comuns se destacam em relação aos usos da literacia em saúde.

Um desses aspectos é a necessidade de se deslocar do emprego de testes padronizados e do foco na dimensão funcional. Indivíduos e grupos acionam não apenas suas habilidades de leitura e escrita, mas também diferentes saberes, identidades, valores e crenças nos modos de significação e utilização de informações sobre saúde. Desse modo, as aplicações, em qualquer área da saúde, precisam considerar a perspectiva multidimensional sobre a literacia em saúde, a fim de construir ações e produtos mais condizentes com a realidade das pessoas e coletividades e mais efetivos em relação a resultados de saúde positivos. Outro aspecto refere-se à importância de se pensar a literacia para além do contexto clínicoassistencial, que é tradicionalmente trabalhado em estudos do campo.

É necessário pensar também nos hábitos e nas condições de vida e em estratégias que se voltem para a dimensão da promoção da saúde e da educação. Um terceiro aspecto refere-se à ruptura com abordagens transmissionistas-normativas, históricas no campo da comunicação em saúde (ARAÚJO; CARDOSO, 2007). Não basta fornecer informação, instruir sobre o que deve ou não ser feito pelo indivíduo ou pela comunidade, ou presumir que as pessoas não sabem ou não conseguem entender determinada informação. Conforme aponta o conceito de literacia, inúmeros fatores estão envolvidos no processo de compreensão da informação sobre saúde. Além disso, o processo de tomada de decisão não é linear. Nesse sentido, a aplicação da literacia em saúde contribui para que isso seja considerado e incorporado no desenvolvimento de estratégias e ações - sobretudo se levarmos em conta a área da comunicação em saúde. O último aspecto 
comum a ser destacado refere-se à necessidade de se pensar a literacia não apenas a partir do debate teórico que há sobre ela, mas também a partir das práticas e das situações de saúde que se configuram no cotidiano dos serviços.

Enquanto o primeiro capítulo foca na aplicabilidade da literacia em saúde, o segundo volta-se para a dimensão das políticas públicas. Intitulado 'A literacia em saúde nas políticas de saúde', ele apresenta como o conceito tem sido trabalhado no contexto de formulação e implementação de políticas públicas, nos contextos internacional e nacional. Peres, Rodrigues e Silva (2021) indicam que, desde o fim dos anos 2000 e início dos anos de 2010, houve um aumento na inclusão da literacia em saúde em políticas. Países como Estados Unidos, Canadá e Portugal, além da União Europeia, são exemplos nesse sentido.

No Brasil, o campo ainda é incipiente, e não há diretrizes voltadas especificamente para a incorporação da literacia em saúde em programas e políticas do Sistema Único de Saúde (SUS). Porém, assim como mostram os autores do livro, é possível observá-la no escopo da Política Nacional de Alimentação e Nutrição (PNAN), da Política Nacional de Promoção da Saúde (PNPS) e da Política Nacional de Atenção Básica (PNAB).

Tal como apresentado no capítulo, políticas de saúde orientadas pela literacia em saúde podem contribuir para a redução de iniquidades. Programas que visem incrementar os níveis de literacia podem melhorar resultados de saúde individuais e coletivos, fomentando inclusive o autocuidado, o aumento na qualidade de vida e o acesso ao uso efetivo dos serviços de saúde. Embora a incorporação da literacia em saúde na formulação de políticas públicas tenha avançado nas últimas décadas, um longo caminho precisa ser percorrido.

Conforme apontam Peres, Rodrigues e Silva (2021), entraves ainda se impõem na implementação de programas, ações e serviços de literacia em saúde. Políticas orientadas pela literacia podem contribuir, entre outros aspectos, para aprimoramento na relação entre profissionais de saúde e usuários; e para a educação permanente e a problematização do cotidiano do trabalho e dos serviços de saúde. Nesse sentido, parece ser fundamental um investimento maior por parte dos formuladores de políticas e gestores para que a literacia em saúde seja efetivamente incorporada às políticas públicas.

O terceiro capítulo mostra a atualidade e a importância do debate sobre literacia em saúde. Denominado 'A literacia em saúde no marco da pandemia de Covid-19', ele estabelece um diálogo fundamental e estratégico com a crise sanitária em curso, instaurada pela disseminação global do novo coronavírus a partir do primeiro semestre de 2020.

Em agosto de 2021, o Brasil possuía mais de 20 milhões de casos e 570 mil óbitos por Covid-19 (FIOCRUZ BAHIA, 2020). O desempenho do governo federal tem sido pífio no combate à pandemia, com posturas que incluem críticas a medidas preventivas cientificamente comprovadas, propaganda de medicamentos ineficazes para a Covid-19, entre outras. Some-se a isso uma infodemia, isto é, uma produção e disseminação excessiva de informações, dificultando a seleção de conteúdos confiáveis. Sobre esse cenário, Peres, Rodrigues e Silva (2021) propõem algumas reflexões.

Uma dessas reflexões refere-se às possíveis aproximações entre literacia em saúde, literacia científica e divulgação sobre ciência e tecnologia. A pandemia da Covid-19 evidencia a importância de considerar e analisar as relações entre os diferentes modos de acesso, a significação e os usos da informação sobre saúde. Conforme discutem os autores, explicita também a importância da literacia científica, isto é, aquilo que o público necessita conhecer sobre a ciência e as dinâmicas de produção de conhecimento científico. Nesse sentido, um exemplo para pensarmos é o do uso de máscaras. Trata-se de uma das principais e mais eficazes medidas não farmacológicas de prevenção à Covid-19. Há mais de um ano, campanhas têm frisado a importância do uso de máscaras em locais públicos. Porém, até o momento, há pessoas que insistem em não utilizá-la, inclusive diminuindo ou invalidando a sua importância. Desse modo, o debate proposto por 
Peres, Rodrigues e Silva (2021) indica que, para que sejam efetivas, estratégias de prevenção e de combate à Covid-19 - ou outra situação epidemiológica - necessitam considerar não apenas os diferentes domínios de literacia em saúde de indivíduos e grupos, mas também os conhecimentos que estes possuem em relação à ciência.

Peres, Rodrigues e Silva (2021) também apontam para o papel estratégico que a divulgação científica assume nesse contexto. Diante da infodemia, a divulgação pode contribuir para a circulação de informações confiáveis e compreensíveis, facilitando o entendimento sobre a situação e sensibilizando indivíduos em relação ao combate ao novo coronavírus. Desde o início da pandemia, especialistas e instituições de diferentes áreas têm utilizado mídias sociais para compartilhar informações sobre a Covid-19. Entretanto, assim como ressaltado pelos autores, ainda é necessário ampliar e fortalecer as estratégias de divulgação científica, inclusive para o cenário pós-pandemia. Para tanto, vale lembrar que são necessários maior investimento público e maior valorização institucional - algo complexo, considerando-se o atual cenário de sucateamento da educação, da ciência e da tecnologia.

Outro aspecto abordado por Peres, Rodrigues e Silva (2021) refere-se às demandas da literacia em saúde sobre a Covid-19. Os autores elaboram exemplos de demandas a partir dos modelos de Don Nutbeam e de Christina Zarcadoolas, Andrew F. Pleasant e David S. Greer. Ao fazê-lo, eles explicitam a diversidade de necessidades de literacia em saúde que se configuram em um contexto pandêmico como o atual. Precisamos considerar que é a partir dessa diversidade que estratégias de comunicação em saúde devem ser elaboradas, a fim de que contribuam efetivamente para o cuidado e a promoção da saúde frente à Covid-19.

Diante de um conceito polissêmico e ainda pouco explorado no campo da saúde, é possível que não existam entendimentos claros em relação ao que ele é ou não é e às suas implicações. Nesse sentido, o quarto e último capítulo, intitulado 'Um diálogo com o leitor', adota um tom pessoal, didático e conciso para explicar quais interpretações equivocadas devem ser evitadas, contribuindo para que a leitura da obra seja encerrada com um melhor entendimento sobre o assunto.

Cinco pontos são elencados por Peres, Rodrigues e Silva (2021). O primeiro é a necessidade da literacia em saúde ser mais desenvolvida e menos mensurada. É preciso transpor o foco do funcionamento de testes e habilidades e se voltar para outro: a construção de estratégias educativas dialógicas. O segundo ponto refere-se aos limites da educação no contexto da literacia em saúde. Por meio da educação, é possível construir novos sentidos e conhecimentos. Entretanto, os autores frisam que isso não ocorre da mesma forma, com todas as pessoas e em todos os contextos. Para que seja transformador, é necessário que o processo de ensino-aprendizagem seja dialógico e inclusivo.

Oterceiro ponto trabalhado por Peres, Rodrigues e Silva (2021) refere-se às abordagens transmissionistasnormativas. Os campos da educação e da comunicação em saúde tradicionalmente basearam suas estratégias e ações num modelo de transmissão de informação linear, unidirecional, caracterizado por conceber o indivíduo tão somente como um receptor (ARAÚJO; CARDOSO, 2007). Tal abordagem desconsidera a complexidade que há nos processos de informação e comunicação e a dimensão da literacia em saúde neles. O quarto ponto é um alerta para que não se confunda a promoção da autonomia e do empoderamento pela literacia em saúde como uma transferência de responsabilidade ao indivíduo, esquecendo o papel que demais agentes e estruturas têm nesse processo. Por fim, no capítulo final do livro, o quinto ponto trabalhado pelos autores refere-se à linguagem. Os autores atentam que, embora seja uma dimensão importante, a literacia em saúde não se resume à linguagem: devem ser considerados também seus demais domínios.

Ao apresentar o conceito e o campo da literacia em saúde, Peres, Rodrigues e Silva (2021) mostram a atualidade e a centralidade que o tema assume ao pensarmos as práticas e os processos da saúde pública, sobretudo aqueles que se estabelecem na interface entre informação, comunicação e saúde. O campo midiático desempenha um papel fundamental, ao fixar discursos e representações sobre saúde na contemporaneidade 
(SACRAMENTO; BORGES, 2020). As tecnologias digitais tornam-se uma das principais fontes de informação sobre saúde, embora o conteúdo acessado e compartilhado por meio delas nem sempre seja confiável, correto ou compreensível (PEREIRA NETO; LIMA; BARBOSA; SCHWARTZ, 2019).

Apesar da crítica, a abordagem transmissionista ainda persiste em estratégias de comunicação em saúde. Nesse contexto, a literacia em saúde coloca-se como um construto-chave não apenas para romper com uma lógica linear, normativa e paternalista nos processos e nas ações de informação e comunicação em saúde, mas também para considerar as especificidades e condições dos sujeitos do sistema de saúde e o cenário midiático que caracteriza a atualidade.

Tal como é frisado ao longo do livro, níveis mais altos de literacia relacionam-se com melhores resultados de saúde. Desse modo, a discussão proposta por Peres, Rodrigues e Silva (2021) aponta para a necessidade de ampliar os estudos no campo, assim como suas aplicações e incorporações ao cotidiano dos serviços de saúde. Ao fazê-lo, o campo da saúde pública pode construir ações e processos que contribuam para o empoderamento individual e coletivo, para a promoção da saúde e para um cuidado mais dialógico e alinhado às necessidades dos sujeitos e das coletividades.

\section{REFERÊNCIAS}

ARAÚJO, Inesita Soares de; CARDOSO, Janine Miranda. Comunicação e saúde. Rio de Janeiro: Editora Fiocruz, 2007.

FIOCRUZ BAHIA. Painel de monitoramento. Salvador: Fiocruz Bahia, 2020. Disponível em: https:// coronavirus.bahia.fiocruz.br/category/painel-monitoramentol. Acesso em: 13 ago. 2021.

LÉVY, Pierre. Cibercultura. São Paulo: Editora 34, 1999.

PEREIRA NETO, André; LIMA, Julyane Felipette; BARBOSA, Leticia; SCHWARTZ, Eda. Internet, expert patient, and empowerment: activity profiles in virtual communities of chronic kidney patients. In: PEREIRA NETO, André; FLYNN, Matthew B. (Orgs.). The Internet and health in Brazil: challenges and trends. Cham: Springer Nature, 2019. p. 87-111.

PERES, Frederico; RODRIGUES, Karla Meneses; SILVA, Thais Lacerda e. Literacia em saúde. Rio de Janeiro: Editora Fiocruz, 2021. (Temas em Saúde).

SACRAMENTO, Igor; BORGES, Wilson Couto. Representações midiáticas da saúde. Rio de Janeiro: Editora Fiocruz, 2020 